\title{
Correction to: Association of main folate metabolic pathway gene polymorphisms with neural tube defects in Han population of Northern China
}

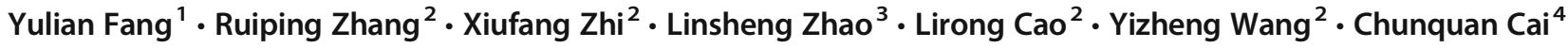

Published online: 14 February 2018

(C) Springer-Verlag GmbH Germany, part of Springer Nature 2018

\section{Correction to: Child's Nervous System https://doi.org/10.1007/s00381-018-3730-0}

The original version of this article unfortunately contained an error.

The authors apologize to have sent an incorrect grant number for the National Natural Science of Foundation of China. The correct number is 81771589 .

The online version of the original article can be found at https://doi.org/ 10.1007/s00381-018-3730-0

\footnotetext{
Chunquan Cai

cqcns6@126.com

1 Institute of Pediatrics, Tianjin Children's Hospital, Beichen District, Tianjin, China

2 Graduate College of Tianjin Medical University, Heping District, Tianjin, China

3 Department of Pathology, Tianjin Children's Hospital, Beichen District, Tianjin, China

4 Department of Neurosurgery, Tianjin Children's Hospital, Beichen District, Tianjin, China
} 